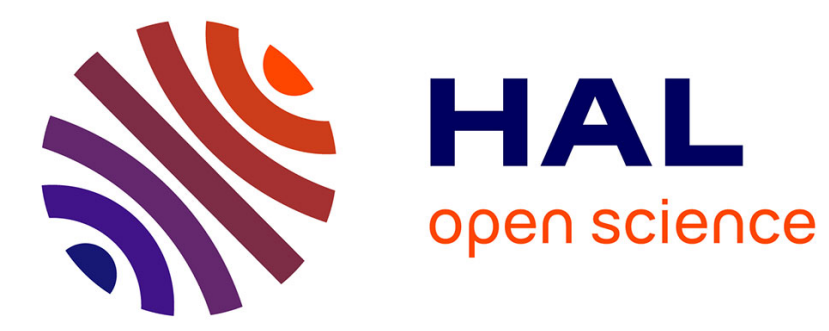

\title{
PLM Adoption Model for SMEs
}

Mourad Messaadia, Fatah Benatia, David Baudry, Anne Louis

\section{To cite this version:}

Mourad Messaadia, Fatah Benatia, David Baudry, Anne Louis. PLM Adoption Model for SMEs. 14th IFIP International Conference on Product Lifecycle Management (PLM), Jul 2017, Seville, Spain. pp.13-22, 10.1007/978-3-319-72905-3_2 . hal-01764212

\section{HAL Id: hal-01764212 \\ https://hal.inria.fr/hal-01764212}

Submitted on 11 Apr 2018

HAL is a multi-disciplinary open access archive for the deposit and dissemination of scientific research documents, whether they are published or not. The documents may come from teaching and research institutions in France or abroad, or from public or private research centers.
L'archive ouverte pluridisciplinaire HAL, est destinée au dépôt et à la diffusion de documents scientifiques de niveau recherche, publiés ou non, émanant des établissements d'enseignement et de recherche français ou étrangers, des laboratoires publics ou privés. 


\title{
PLM Adoption Model for SMEs
}

\author{
Mourad. Messaadia ${ }^{1}$, Fatah. Benatia ${ }^{2}$, David. Baudry ${ }^{1}$, Anne. Louis ${ }^{1}$ \\ ${ }^{1}$ CESI/IRISE, Rouen, France \\ ${ }^{2}$ Laboratoire de Mathématiques Appliquées, Université M.Khider, Biskra, Algérie \\ \{mmessaadia, dbaudry, alouis\}@cesi.fr; \\ ffatahbenatia\} @hotmail.com
}

\begin{abstract}
PLM adoption can be a source of competitiveness and sustainability for SMEs. In the other hand, the introduction of new ICT (Information and communication technologies) technologies, such PLM, is a complex process that involves challenging the existing organization, not only in terms of information flow but also the human resources management and OEM/Suppliers relationship level. As seen in literature review, there are a number of factors that facilitate the adoption of ICT technology, but we also identified a number of obstacles that will need to act as the adoption takes place. The paper focused on issues regarding the ICT adoption, especially PLM solutions by SMEs. Based on investigation, this paper proposes a mathematical model of PLM adoption.
\end{abstract}

Keywords: PLM, ICT Adoption, SMEs, Data analysis

\section{INTRODUCTION}

The literature review has addressed the topic of PLM from different angles. However, the adoption aspect was only dealt by a few works such [1] where author proposes statistical tools to improve the organizational adoption of new PLM systems and highlights on the importance of survey early in the PLM introduction process; [2] provides a review of the main developments in the AHP (Analytical Hierarchy Process) methodology as a tool for decision makers to be able to do more informed decisions regarding their investment in PLM; [3] on the adoption of PLM IT solutions and discussed the relationship between "PLM adopter" and "lifecycle-oriented" companies in order to achieve the adoption aspect we have considered PLM as an innovate ICT for SMEs. Thus we integrated works on ICT and innovation adoptions.

ICT technology is one of the ways, at the disposal of a company to increase its productivity. ICT can reduce business costs, improve productivity and strengthen growth possibilities and the generation of competitive advantages [1]. Despite the work done and large companies evolution in terms of PLM, SMEs still have difficulties to understand all the potential of such technologies [5]. Their adoption of ICT is slow and late, primarily because they find that ICT adoption is difficult [6] and SMEs adoption is still lower than expected.

When implementing a PLM solution in a company, the implementation difficulties are directly dependent on the complexity of the organization, costs and the possible

adfa, p. 1, 2011.

(C) Springer-Verlag Berlin Heidelberg 2011 
opacity of the real behaviours in the field. Indeed, the implementation of PLM solution seems to scare SMEs in terms of resource costs and deployment.

The integration of the PLM solutions and its adoption by the SMEs has succeeded the interest of several research works. Among these research works we distinguish those on adoption process improving through statistical tools [1]. In the same way authors in [7] conducted an investigation around 1500 enterprises and analyse the process adoption. This investigation shows that size on enterprise, human capital of the workforce and the geographic proximity with large firms has an impact on ICT adoption. In another hand, we find investigation based on empirical analysis which highlights the role of management practices, especially the manager, and quality control on the ICT adoption.

Another investigation was conducted on a thousand firms in manufacturing in Brazil and India and examines the characteristics of firms adopting ICT and the consequences of adoption for performance [8]. In addition to previous results, they show the impact of educational system and the positive association between ICT adoption and education. Several barriers to IT adoption have been identified, including: lack of knowledge about the potential of IT, a shortage of resources such financial and expertise and lack of skills [6].

According to [9] the skill workers have an impact on ICT adoption. Workers with high (low) proportions of skill can have a comparative advantage (disadvantage) in minimizing the costs both of ICT adoption and of learning how to make best use of ICTs.

An investigation of works done on ICT adoption conclude on the importance to analyse the impact on ICT system implementation and adoption processes and how they do so, and how implementation and adoption processes could be supported on the organizational, group, and individual levels [10]. Based on previous works, we will consider that PLM is an innovative ICT solution for SMEs.

Next paragraph will introduce the problem statement and context of study. Third paragraph is on the proposed the model of PLM adoption based on quantitative KPIs. The fourth paragraph highlights the obtained results and their discussion. Finally, we conclude and discuss future work on how to improve and deploy our model.

\section{STUDY CONTEXT}

The first initiative of this work was conducted during the INTERREG project called "BENEFITS" where different adoption KPI's was identified [11].

On the basis of an analysis of the various studies carried out with several companies, it is possible to collect different indicators. These indicators have been classified according to 4 axes identified through PLM definitions analysis. The 4-axis structure (Strategy, Organisation, Process and Tools) seemed clear and gave a good visibility to the impact of the indicators on the different levels of enterprise [11].

For our work, Survey conducted followed different steps from questionnaire designing until data analysis [12]. One of problems faced during questionnaire design is the decision of what questions to ask, how to best word them and how to arrange the 
questions to yield the information required. For these questions were conducted on the basis of indicators, words were reviewed by experts and finally we reorganised questions according to new 4 axes: Human Factors, Organisational Factors, Technical Factors and Economic Factors. This new decomposition does not affect the indicators but brings a fluidity and easier understanding for the interviewees (SMEs).

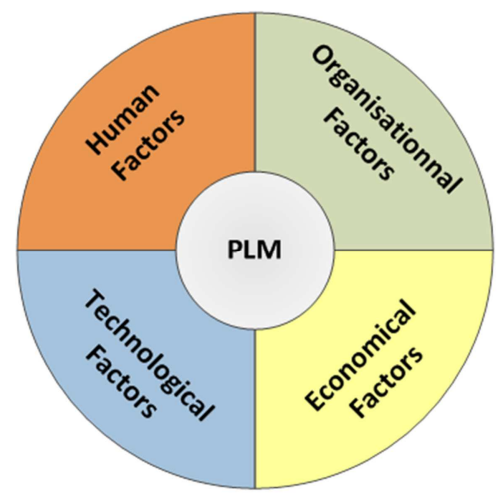

Fig.1.PLM axis structuration

Also, the objective of the investigation is to understand the needs of SMEs according to the introduction of digital technology within the automotive sector and to anticipate the increase in competence needed to help these SMEs face the change by setting up the necessary services and training. The survey was conducted on a panel of 33 companies (14 with study activities and 19 with manufacturing activities) of which $50 \%$ are small structures as shown in Fig.2.

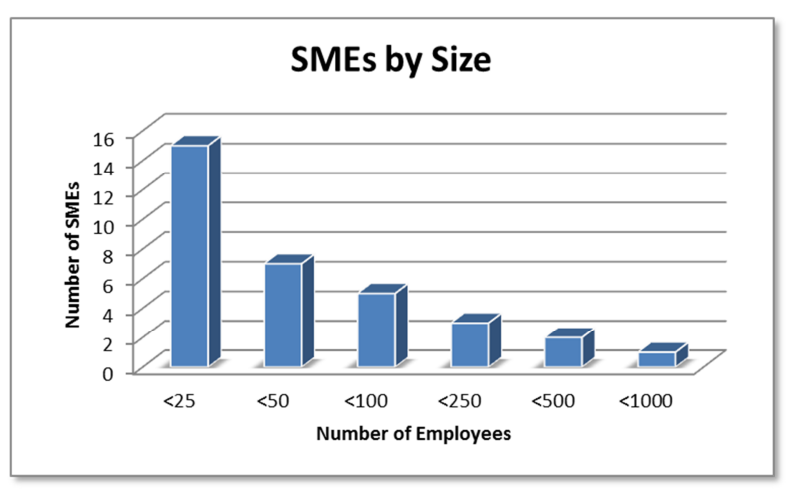

Fig.2.Panel of SMEs interviewed

\section{PLM ADOPTION INDICATORS}

The concept of adoption may be defined as a process composed of a certain number of steps by which a potential adopter must pass before accepting the new product, 
new service or new idea [13]. Adoption can be seen as an individual adoption and organizational adoption. The individual one focuses on user behaviour according to new technology and have an impact on the investment in IT technology [14]. In the organisational adoption the organisation forms an opinion of the new technology and assesses it. Based on this, organisation makes the decision to purchase and use this new technology [14]. Based on work done in [11] we developed the questionnaire according to adoption factors (Table 1.).

Table 1.Adoption factors according to the $4^{\text {th }}$ axes

\begin{tabular}{|c|c|}
\hline Axes & Questions according to adoption factors \\
\hline Human factor & $\begin{array}{l}\text { Ability to assess technological opportunities (FH1) } \\
\text { Resistance to change (FH2) } \\
\text { The learning effects on previous use of ICT technology (FH3) } \\
\text { Relative advantage (FH4) } \\
\text { Risk aversion (FH5) } \\
\text { Emphasis on quality (FH6) }\end{array}$ \\
\hline $\begin{array}{l}\text { Organisational } \\
\text { factor }\end{array}$ & $\begin{array}{l}\text { Average size of effective of SME between } 50 \text { and } 200 \text { (FO1) } \\
\text { Age of SMEs (FO2) } \\
\text { Competitive environment (FO3) } \\
\text { Rank of SME (FO4) } \\
\text { Geographical proximity (FO5) } \\
\text { Number of adopters (FO6) } \\
\text { Interdependencies Collaboration (FO7) } \\
\text { Existing leading firms (OEM) in your economic environment } \\
\text { (FO8) } \\
\text { Informal communication mode (FO9) } \\
\text { Existing Innovation process (FO10) } \\
\text { Knowledge Management (FO11) } \\
\text { Process synchronization (FO12) } \\
\text { Existing R\&D activities (FO13) } \\
\text { Existing certified (QM) system (FO14) }\end{array}$ \\
\hline $\begin{array}{l}\text { Technological } \\
\text { factor }\end{array}$ & $\begin{array}{l}\text { The position of SME related to ICT technologies (FT1) } \\
\text { Interoperability (FT2) } \\
\text { Ergonomic (FT3) } \\
\text { Compatibility with similar technology (FT4) } \\
\text { Compatibility with needs and existing process (FT5) } \\
\text { How is evaluated before adopting technology (FT6) } \\
\text { Have you had the opportunity to test the technology before its } \\
\text { adoption (FT7) } \\
\text { Complexity (FT8) } \\
\text { The frequency of new technology integration (FT9) } \\
\text { Level of skill and knowledge (FT10) } \\
\text { Existing software (PDM, CAD/CAM,ERP) (FT11) }\end{array}$ \\
\hline Economical & Indirect costs (FE1) \\
\hline
\end{tabular}




\begin{tabular}{l|l}
\hline factor & Existing R\&D process (FE2) \\
& Expected profitability (FE3) \\
& Merger-acquisition (M\&A) Strategy (FE4) \\
\hline
\end{tabular}

\section{QUESTIONNAIRE ANALYSIS}

The previous step was the construction of the questionnaire by methodological tool with a set of questions that follow in a structured way (Fig. 3). It is presented in electronic form and was administered directly through face to face and by phone.

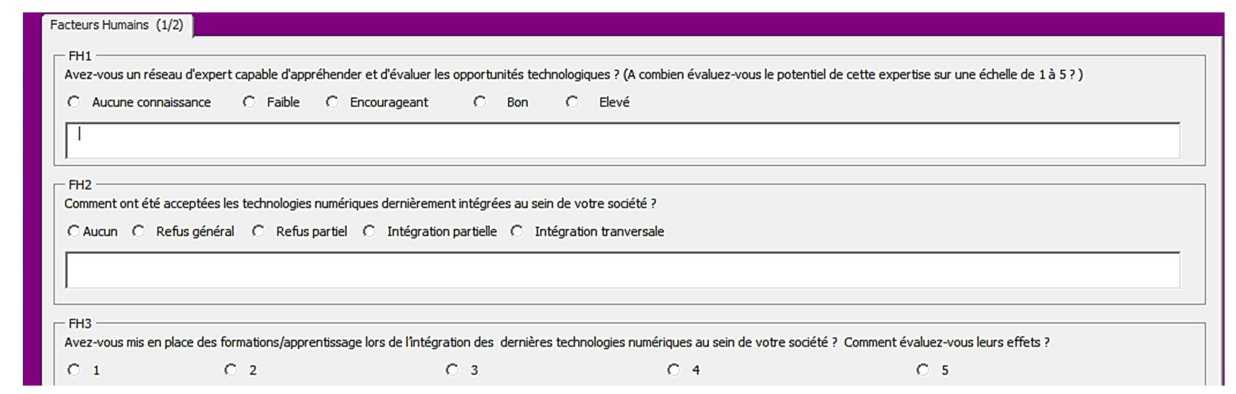

Fig. 3. PLM-Eval-Tool: questionnaire

The questions were asked by a PLM consultant with directors, engineers \& technicians for increasing responses validity. The questions were design based on Likert scale and for five levels; in addition, a commentary frame has been added to question evaluation (from 1 to 5) which can be filled by the direct exchanges during the interview.

Once responses evaluated we need to describe the adoption model in mathematical way. Based on results we can write the dependencies equation which makes the link between the PLM Level $\left(P L M_{i}\right)$ and adoption factors $(O, H, T$ and $E)$.

$$
P L M_{i}=a H_{i}+b O_{i}+c T_{i}+d E_{i}+\varepsilon_{\mathrm{i}}
$$

For: $i=1, \ldots, n$, the hypothesis related to the model (eq.1) is the distribution of the error $\varepsilon$ is independent and the error is centred with constant ance $\varepsilon_{i} \sim N\left(0, \sigma^{2}\right) ; \sigma^{2}=\operatorname{var}\left(\varepsilon_{i}\right)$

In order to conclude that there is a significant relationship between PLM level and Adoption factors, the Regression (eq.1) is used during estimation and to improve the quality of the estimates. The first step is to calculate the adoption factors according to:

$$
\begin{aligned}
H_{i} & =\frac{1}{n_{H}} \sum_{j=1}^{n_{H}} H_{i j}, n_{H}=\text { number of questions related to the humain factor } H \\
O_{i} & =\frac{1}{n_{O}} \sum_{j=1}^{n_{O}} O_{i j}, \mathrm{n}_{0}, \text { number of questions related to the Organisation factor } 0
\end{aligned}
$$




$$
\begin{gathered}
T_{i}=\frac{1}{n_{T}} \sum_{j=1}^{n_{T}} T_{i j}, n_{T}=\text { number of questions related to the technogical factor } T \\
E_{i}=\frac{1}{n_{E}} \sum_{j=1}^{n_{E}} E_{i j}, n_{E}=\text { number of questions related to the economical factor } E
\end{gathered}
$$

Once the fourth factors calculated, the matrix form of our model becomes:

$$
\left(\begin{array}{c}
P L M_{1} \\
P L M_{2} \\
\vdots \\
P L M_{n}
\end{array}\right)=\left(\begin{array}{cccc}
H_{11} & O_{11} & T_{11} & E_{11} \\
H_{21} & O_{21} & T_{21} & E_{21} \\
\vdots & \vdots & \vdots & \vdots \\
H_{n 1} & O_{n 1} & T_{n 1} & E_{n 1}
\end{array}\right)\left(\begin{array}{l}
a \\
b \\
c \\
d
\end{array}\right)+\left(\begin{array}{c}
\varepsilon_{1} \\
\varepsilon_{2} \\
\vdots \\
\varepsilon_{n}
\end{array}\right) \Leftrightarrow P L M=Y=X B+\mathrm{E}
$$

For resolving our equation (Eq.2) we need to calculate the estimated matrix $B$. With estimated $B$ called:

$$
\hat{B}=\left(X^{t} X\right)^{-1} X^{t} Y
$$

Through all these equations (observation) we can give the general regression equation of PLM.

$P L M=a H+b O+c T+d E+\varepsilon$

The methodology adopted started by determining (estimating) $a, b, c, d$ parameters of the multiple-regression function. The result of estimation is defined by: $\hat{a}, \hat{b}, \hat{c}, \hat{d}$. For this, we choose the method of "mean square error" calculated through Matlab. In the second step, we calculate the dependency between PLM level (result of multipleregression) and the adoption factors $(H, O, T$ and $E$ ) by the regression coefficient (R), especially the Determination Coefficient (D).

Where:

$$
\begin{aligned}
& D=R^{2}=\frac{S S R}{S S T}, S S R=\text { Some square Regression; } S S T=\text { Total Some Square; } \\
& S S E=\text { Some square Error } . S S T=S S R+S S E= \\
& \text { If }|R| \rightarrow 1 \text {, We have a strong dependence and good regression }
\end{aligned}
$$

\begin{tabular}{|c|c|c|c|c|c|c|c|c|c|}
\hline Date de création & Secteur d'activités & Effectif & FH1 & $\mathrm{FH} 2$ & $\mathrm{FH} 3$ & $\mathrm{FH} 4$ & FH5 & FH6 & FO1 \\
\hline 01/01/1905 & l'ingénierie des métiers de l'automobile & 100 & 5 & 3 & 3 & 4 & 3 & 5 & 3 \\
\hline $01 / 01 / 1995$ & Fabrication de cartes électroniques assemblées & 17 & 5 & 1 & 4 & 3 & 1 & 5 & 3 \\
\hline 01/01/1984 & I'automobile, l'aéronautique et la défense & 15 & 4 & 4 & 3 & 4 & 1 & 4 & 3 \\
\hline
\end{tabular}

\subsection{Numerical Results}

After the investigation the PLM-Eval-Tool generates a data table (Fig. 4) of evaluated responses that will be used to build our adoption model.

Fig.4. Brief view of collected data 
Once the data collected, we applied our approach for obtaining the estimated parameters $\hat{a}, \hat{b}, \hat{c}, \hat{d}$ through (Eq.3).

$$
\left(\begin{array}{l}
\hat{a} \\
\hat{b} \\
\hat{c} \\
\hat{d}
\end{array}\right)=\left(\begin{array}{l}
0.0697 \\
0.6053 \\
0.1958 \\
0.1137
\end{array}\right)
$$

With $R^{2}=0.9841$ which is considered as a very good regression, and validate the proposed equation (Eq.1).

The numerical result equation is:

$P L M_{\text {Evaluation }}=0.0697 H_{i}+0.6053 O_{i}+0.1958 T_{i}+0.1137 E_{i}$

\subsection{Result discussion}

Concerning the "Error" we will consider the highest one which is equal to $\frac{1}{n} \sum \varepsilon_{i}^{2}=$ $\frac{0.4217}{33}=0.0128$. This means that all values of PLM_Evaluation will be considered with \pm 0.0128 . We can also determine confidence interval for the parameters $\mathrm{a}, \mathrm{b}, \mathrm{c}$ and $\mathrm{d}$ using the student law $\mathrm{t}_{\alpha, \mathrm{k}}$, where $\alpha$ is the Confidence threshold, or the Tolerance error rate, the choice of the value $\alpha$ in our case is $\alpha=0.05$ and $k=4$ is the degree of freedom (the number of parameters) $\widehat{\sigma}_{\mathrm{a}}$ is the standard deviation (the square root of the variance). In our case $t_{\alpha, k}=t_{0.05,4}=2.132$ (Fig.5).

\begin{tabular}{||c|ccccccccccc||}
\cline { 2 - 12 } & 0.25 & 0.20 & 0.15 & 0.10 & 0.05 & 0.025 & 0.010 & 0.005 & 0.0025 & 0.0010 & 0.0005 \\
\hline 1 & 1.000 & 1.376 & 1.963 & 3.078 & 6.314 & 12.71 & 31.82 & 63.66 & 127.3 & 318.3 & 636.6 \\
2 & 0.816 & 1.061 & 1.386 & 1.886 & 2.920 & 4.303 & 6.965 & 9.925 & 14.09 & 22.33 & 31.60 \\
3 & 0.765 & 0.978 & 1.250 & 1.638 & 2.353 & 3.182 & 4.541 & 5.841 & 7.453 & 10.21 & 12.92 \\
4 & 0.741 & 0.941 & 1.190 & 1.533 & 2.132 & 2.776 & 3.747 & 4.604 & 5.598 & 7.173 & 8.610
\end{tabular}

Fig.5. Student table

Figure (5), shows Student's law with "k" degrees of latitude and different values of $\alpha=0.0005 ; \ldots ; 0.25$. The student test can be applied to $\mathrm{a}, \mathrm{b}, \mathrm{c}$ and $\mathrm{d}$ to determine the parameters influencing the PLM. By testing the null hypothesis $H_{0}: a=0$ against the alternative hypothesis $H_{1}: a \neq 0$.

Using data from a sample, the probability that the observed values are the chance result of sampling, assuming the null hypothesis $\left(H_{0}\right)$ is true, is calculated. If this probability turns out to be smaller than the significance level of the test, the null hypothesis is rejected.

$$
\left\{\begin{array}{l}
H_{0}: a=0 \\
H_{1}: a \neq 0
\end{array}\right.
$$

For this we will calculate: $T=\frac{|\hat{a}|}{\widehat{\sigma}_{a}}$ 
Then we will compare it to the value of $t_{0,05 ; 4}=2,13$

If $\mathrm{T}<t_{0,05 ; 4}=2,13$, we accept $H_{0}: a=0$, the $\mathrm{H}$ parameter does not influence the realization of PLM and we will then recreate another equation of regression without $\mathrm{H}$. The same analysis was done for $\mathrm{b}, \mathrm{c}, \mathrm{d}$.

\section{DISCUSSION}

Once the model developed another aspect of the analysis was explored, that of the recommendations. Effectively, the PLM-Eval-Tool offer also a view (fig.6.) the results according to such factors as change management, structured sharing, extended enterprise, evaluation capacity and willingness to integrate. These factors are seen as a numerical focus, and first returns on SMEs analysis are:

- $30 \%$ of companies consider themselves to be under-equipped regarding to information technology.

- Companies recognize that information technology is very much involved in the development process, but for the majority of them organizational aspects and informal exchanges are decisive.

- They believe that they have the in-house skills to anticipate and evaluate technological opportunities and are very "open" to the integration of new technologies.

- SMEs are pragmatic and are waiting for the opportunity of a project or a new client to introduce software and associated training: design or simulation tool, ENX link, digital models ...

- Companies often note a gain when introducing a new technology but highlight compatibility issues with existing technologies, including ERP. (Systematic evaluation on demonstrator before implementation)

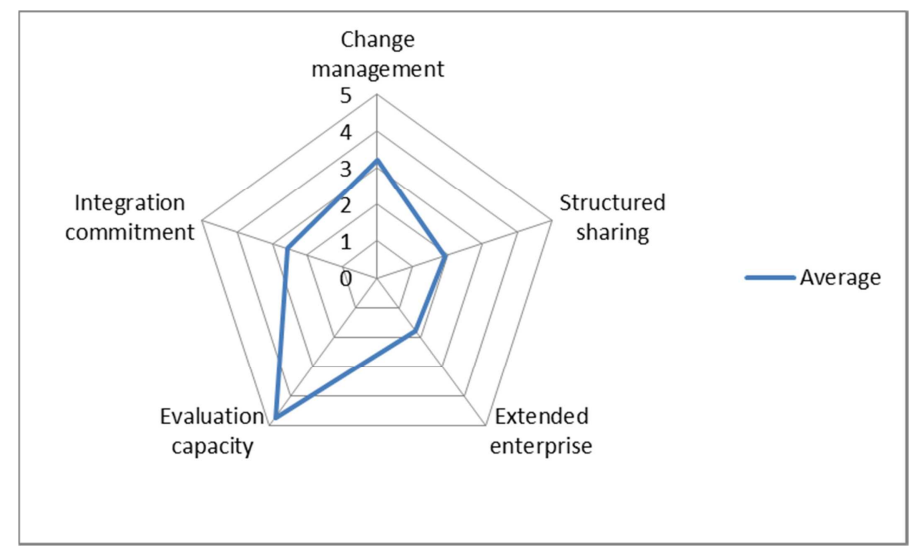

Fig.6. Radar showing the average of the results obtained by the companies that responded to the questionnaire. Scaling from 0: Very low to 5: Very good 
- The adoption of digital technology by their partners and suppliers is not a concern today.

- A concern to better structure their data and define their workflow in particular around knowledge management and collaborative innovation.

- A request for training on tools, existing gateways for data transfer, standards and standards to be used throughout the product lifecycle.

- A request for information on the potential of SaaS solutions and shared services.(Design, simulation, exchange platform)

According to obtained results, here is a list of first actions that we propose to implement:

- To make the players in the sector aware of the evolution of this increasingly digital environment.

- Diagnose the existing digital chaining in companies to promote the benefits of the PLM approach. (Processes, tools, skills, etc.)

- To propose levers of competitiveness by the identification of "Mutualized Services" and "Software as a Service" solutions.

- To propose devices to gain skills and accompany the change management of manufacturers, equipment manufacturers, to the SMEs in the region.

\section{CONCLUSION}

The statistical analysis allowed us to develop a mathematical model to evaluate the adoption of an SME in terms of PLM. Thus, SMEs will be able to carry out a first self-evaluation without calling on honest consultants. However, this model will have to improve with more SMEs results and taking into account the different activity sectors aspect.

As future work, we envisage to work on several cases studies (deployment on France) in order to improve the mathematical model. Also, another work will be carried out in order to generate recommendations automatically. The aim of this approach is to offer SMEs a tool for analysis and decision-making for the upstream stage in the introduction or adoption of PLM tools.

\section{ACKNOWLEDGEMENT}

Acknowledgement is made to PFA automotive which has initiated this study around the technical information, processes and skills management system, which provides data structuring for the extended company with the support of the DIRECCTE IdF, the RAVI for the identification of companies and the CETIM to conduct the interviews. 


\section{REFERENCES}

1. Bergsjö, D. (2011, July). PLM Adoption Through Statistical Analysis. In The proceedings of 11 th International Conference on Product Lifecycle Management. Edited by JH, Pels et al., PLM (Vol. 11, pp. 11-13).

2. Ristova, E., \& Gecevska, V. (2011, September). AHP methodology and selection of an advanced information technology due to PLM software adoption. In Proceedings of the 15th International Scientific Conference on Industrial Systems.

3. Rossi, M., Riboldi, D., Cerri, D., Terzi, S., \& Garetti, M. (2013, January). Product Lifecycle Management Adoption versus Lifecycle Orientation: Evidences from Italian Companies. In PLM (pp. 346-355).

4. Barba-Sánchez, V., Martínez-Ruiz, M. D. P., \& Jiménez-Zarco, A. I. (2007). Drivers, benefits and challenges of ICT adoption by small and medium sized enterprises (SMEs): a literature review. Problems and Perspectives in Management, 5(1), 104-115.

5. Hollenstein, H., The decision to adopt information and communication technologies (ICT): firm-level evidence for Switzerland, In: OECD (Ed.), the Economic Impact of ICT. Measurement, Evidence and Implications. OECD, Paris, 2004, 37-60.

6. Hashim, J. (2015). Information communication technology (ICT) adoption among SME owners in Malaysia. International Journal of Business and Information, 2(2).

7. Fabiani, S., Schivardi, F., \& Trento, S. (2005). ICT adoption in Italian manufacturing: firm-level evidence. Industrial and Corporate Change, 14(2), 225-249.

8. Basant, R., Commander, S. J., Harrison, R., \& Menezes-Filho, N. (2006). ICT adoption and productivity in developing countries: new firm level evidence from Brazil and India.

9. Forth, J., \& Mason, G. (2004). Information and Communication Technology (ICT) adoption and utilisation, skill constraints and firm level performance: evidence from UK benchmarking surveys. National Institute of Economic and Social Research.

10. Korpelainen, E. (2011). Theories of ICT system implementation and adoption-A critical. Aalto Uni-versity publication series, 1, 14-17.

11. Messaadia, M., Baudry, D., Louis, A., Mahdikhah, S., Evans, R., Gao, J., ...\&Mazari, B. (2016). PLM adoption in SMEs context. Computer-Aided Design and Applications, 13(5), 618-627.

12. Franklin, S., \& Walker, C. (Eds.). (2003). Survey methods and practices. Statics Canada. Social Survey Methods Division.

13. Frambach, R. T., \& Schillewaert, N. (2002). Organizational innovation adoption: A multilevel framework of determinants and opportunities for future research. Journal of business research, 55(2), 163-176.

14. Magni, M., \& Pennarola, F. (2008). Intra-organizational relationships and technology acceptance. International Journal of Information Management, 28(6), 517-523. 